\title{
La contratación pública como instrumento de digitalización de las pymes
}

\author{
Zamówienia publiczne jako instrument cyfryzacji MŚP
}

\author{
Javier Miranzo Díaz \\ Universitat Oberta de Catalunya
}

\section{Las pymes en la Unión Europea}

La importancia de las pequeñas y medianas empresas (pymes) para la estructura social y económica de la UE es a todas luces innegable. Tal y como expone la propia Comisión Europea, las pymes representan más del $99 \%$ del total de las sociedades europeas ${ }^{1}$. Estas, además, son en su gran mayoría empresas familiares y constituyen nuestra columna vertebral tanto económica como social. En países como España, este porcentaje un 99,84\% del total de empresas en España 2.884.795, de las cuales eran pyme ${ }^{2}$.

En este marco, la potenciación económica y capacitación de las pymes, y en concreto la digitalización, se ha configurado como un elemento determinante. Si analizamos el estado de la I+D+I empresarial en España, vemos que las empresas españolas invierten poco en activos basados en el conocimiento, no sólo en I+D sino también en otras capacidades empresariales que son importantes para la innovación ${ }^{3}$. El porcentaje sobre el PIB que supone el gasto en I+D ejecutado por el sector empresarial en España es del 0,6\%, lo que supone aproximadamente la mitad del porcentaje en la UE (1,3\%), y muy lejos de países como Suecia, Austria y Alemania, que superan el $2 \%$.

En el European Innovation Scoreboard 2020, tanto España como Polonia aparecen catalogados como "innovadores moderados", dentro de la categorización que hace la $\mathrm{UE}^{4}$, junto con otros países como Italia, Grecia, República Checa, Eslovaquia o Hungría ${ }^{5}$. Es especialmente preocupante que tanto España como Polonia se en-

${ }^{1}$ Comunicación de la Comisión al Parlamento Europeo, al Consejo, al Comité Económico y Social Europeo y al Comité de las Regiones de 10 de marzo de 2020, Un nuevo modelo de industria para Europa, $\operatorname{COM}(2020) 102$ final, p. 2.

${ }^{2}$ Pueden consultarse las cifras oficiales en: Cifras PYME, http://www.ipyme.org/es-ES/publicaciones/ Paginas/estadisticaspyme.aspx.

${ }^{3}$ Ibidem.

${ }^{4}$ Innovadores líderes, innovadores fuertes, innovadores moderados e innovadores modestos.

${ }^{5}$ Sin embargo, dentro de este rango, España tiene una puntuación más alta (92) y Polonia más baja (64). 
cuentran entre los tres peores países (acompañados por Bulgaria), en el indicador dedicado a la innovación interna de las pymes (26 y 16 puntos, respectivamente), con una brecha importante respecto a los primeros países más innovadores en este sentido, como Portugal o Noruega (170 puntos) $)^{6}$.

Ante esta situación, la digitalización de las pymes ha sido uno de los principales ejes de actuación de la UE en su estrategia de desarrollo desde hace años ${ }^{7}$. La prioridad de esta digitalización para la supervivencia de estas pequeñas empresas se ha puesto quizá especialmente de manifiesto a raíz de la crisis provocada por la COVID-19 ${ }^{8}$. Las dificultades para desarrollar actividades presenciales en este contexto y la necesidad de las pymes para sobrevivir a la crisis económica derivada de la situación sanitaria, ha hecho que el $48 \%$ de las pymes hayan invertido en software debido a la crisis, cambiando su plan de inversión en software desde el comienzo de la pandemia. Curiosamente, España (55\%) e Italia (52\%), con un nivel de digitalización de pymes relativamente bajo en relación con la media europea, han sido algunos de los países con mayor número de pymes invirtiendo en nuevos programas informáticos para acelerar el cambio digital debido a la COVID-19 ${ }^{9}$. Estos datos no son sorprendentes, ya que el 35\% de las empresas han tenido que considerar la posibilidad de incorporar nuevos software para fomentar el trabajo en equipo y el $70 \%$ de las empresas han podido adaptar parte o la totalidad de sus ofertas comerciales para poder entregarlas virtualmente.

En este contexto, la Comisión Europea ha reiterado cómo el la digitalización y la implantación de herramientas de IA debe ser considerado como uno de los pilares del desarrollo, de forma que el crecimiento de la capacidad informática y la disponibilidad de datos, así como los avances en los algoritmos, han convertido la IA y las herramientas digitales en una de las tecnologías más estratégicas del siglo $\mathrm{XXI}^{10}$. De igual manera, otras organizaciones, como Digital SME Alliance, han manifestado también sus preocupaciones para crear un mercado único digital armonizado abierto y competitivo y permita que las pequeñas empresas innovadoras prosperen ${ }^{11}$.

${ }^{6}$ European Innovation Scoreboard 2020. Puede cosnultarse en: https://interactivetool.eu/EIS/EIS_2.html\#a.

${ }^{7}$ Véase el análisis que hace la Dirección General de Política de la Pequeña y Mediana Empresa. Análisis sectorial de implantación de las tic en la pyme española, 2011; también B. Gómez Fariñas, La participación de las PYMES en la contratación pública: una visión desde el derecho europeo, „Revista Digital de Derecho Administrativo" 2020, n²4, pp. 161-182.

${ }^{8}$ Véase, por ejemplo, Plan de Digitalización PYMEs 2021-2025, que pretende inyectar importantes cantidades de inversión en este sector para garantizar una recuperación económica lo más ágil posible. Gobierno de España. Plan de Digitalización PYMEs 202-2025, 2021. En el mismo sentido, véase C. de Guerrero Manso, C., ¿Compara Pública de innovación en tiempo de COVID-19?, en Observatorio de los Contratos Públicos 2019, dir. J.M. Gimeno Feliú, Pamplona 2020, pp. 433-458.

${ }^{9}$ J. Molero et. al., Pymes y COVID-19: hacia una recuperación sostenible, 2020.

${ }^{10}$ En particular, puede verse la Comunicación de la Comisión "Inteligencia artificial para Europa", $\operatorname{COM}(2018) 237$ final.

${ }^{11}$ European Digital SME Alliance, Position paper on the Digital Services Act (DSA), 8 September 2020. 


\section{La COVID-19, el Estado de Alarma y los efectos sobre las pymes}

Cuando el 31 de diciembre la Comisión Municipal de Salud de Wuhan (provincia de Hubei, China) notificara una serie de casos de neumonía en la ciudad que podían estar causados por un nuevo coronavirus, pocos podían sospechar el impacto que este nuevo virus tendría en el mundo. Tras ir superando fronteras y, tras llegar a Europa, el 11 de marzo la OMS juzgó que la situación presentaba características lo suficientemente graves como para calificarlo como una pandemia global. Apenas unos días más tarde, el fuerte brote que comenzaba a manifestarse en España hacía que el Estado de la Nación decretara el Estado de Alarma mediante el Real Decreto $463 / 2020$, de 14 de marzo, por el que se declara el estado de alarma para la gestión de la situación de crisis sanitaria ocasionada por el COVID-19. En él se recogían una serie de medidas de confinamiento que paralizaron la práctica totalidad de la actividad social en nuestro país, y por ende, también una parte importante de la actividad económica.

Estas medidas generaron, así, una situación de crisis económica nunca antes vista, debido al carácter radical y artificial de la parálisis económica, frente a las fluctuaciones "naturales", parciales y en mayor o menor grado progresivas que se pueden observar en crisis económicas anteriores. De la noche a la mañana, millones de empresas y operadores económicos dejaron de operar, y por tanto de ingresar beneficios, lo cual podía repercutir esencialmente en (1) despido de trabajadores o (2) cierres de empresas. Todos los operadores económicos se enfrentaron a estas consecuencias, pero las pymes y autónomos, precisamente por el escaso presupuesto y la ausencia de liquidez, se encontraron en una especial situación de exposición y vulnerabilidad antes estos gastos extraordinarios (o más bien, ante la ausencia de ingresos). La falta de ingresos o la minoración de los mismos durante el periodo del estado de alarma dio lugar a la incapacidad financiera de autónomos y pymes para hacer frente al cumplimiento, total o parcial, de sus diversas obligaciones de pago.

Ante este escenario, el Gobierno se vio obligado a aprobar una serie de medidas. Así, existía la posibilidad de acudir a un ERTE regulado por los arts. art. 45, 47 y 51 del Real Decreto Legislativo 1/1995, de 24 de marzo, por el que se aprueba el texto refundido de la Ley del Estatuto de los Trabajadores -flexibilizado posteriormente por el Real Decreto-ley 8/2020, de 17 de marzo, de medidas urgentes extraordinarias para hacer frente al impacto económico y social del COVID-19 y otras normativas posteriores- con el objetivo de mantener puestos de trabajo sin que esto supusiera una carga insoportable para las empresas cuando su actividad económica esté incluida en el anexo del Real Decreto 463/2020, de 14 de marzo, por el que se declara el estado de alarma, y por tanto se ven obligadas a dejar de prestar servicios y cerrar sus puertas temporalmente. Del mismo modo, todas las empresas que no estén incluidas dentro de dicho listado, pero se vean directamente afectadas por la situación de alarma nacional y deban suspender la actividad o reducir las jornadas 
de sus trabajadores, podrán presentar frente a la autoridad laboral competente la solicitud de ERTE.

Esta medida, quizá la más popular, fue complementada con otras disposiciones, como las tomadas por el Real Decreto-ley 7/2020, de 12 de marzo, por el que se adoptan medidas urgentes para responder al impacto económico del COVID-19, sobre el aplazamiento del ingreso de la deuda tributaria correspondiente a todas aquellas declaraciones-liquidaciones y autoliquidaciones desde la fecha de entrada en vigor del presente real decreto-ley y hasta el día 30 de mayo de 2020 (art. 14), así como de la devolución de préstamos concedidos a las pymes por concedidos por la Secretaría General de Industria y de la Pequeña y Mediana Empresa (art. 15). Igualmente, el Real Decreto-ley 8/2020, de 17 de marzo, de medidas urgentes extraordinarias para hacer frente al impacto económico y social del COVID-19 creó una línea de avales para las empresas y autónomos para paliar los efectos económicos del COVID-19, llevó a cabo una ampliación del límite de endeudamiento neto del ICO y creó el Programa Acelera pyme con el objeto de articular un conjunto de iniciativas en colaboración con el sector privado de apoyo a las pymes en el corto y medio plazo ${ }^{12}$. Éste último constituye una ventanilla única de acceso a todas las soluciones, servicios, ayudas y herramientas ofrecidas por entidades colaboradoras, que se centra especialmente en la digitalización de las pymes que les permita operar con garantías en condiciones de teletrabajo ${ }^{13}$.

En esta secuencia temporal, las medidas continuaron con la moratoria para pymes y autónomos en el alquiler de los locales siempre que fueran propiedad de empresas, entidades públicas de vivienda o un gran tenedor grandes tenedores, aprobada por el Real Decreto-ley 15/2020, de 21 de abril, de medidas urgentes complementarias para apoyar la economía y el empleo. En el mismo se incluían, dicha norma adopta también algunas medidas para reforzar la financiación empresarial.

Finalmente, la normativa citada prevé también una serie de medidas excepcionales en materia de contratación que tienen que ver con la necesidad de garantizar la liquidez de las empresas adjudicatarias y la necesaria flexibilidad para adaptar los contratos a las excepcionales circunstancias ${ }^{14}$. Estas medidas, las cuales no entrare-

${ }^{12}$ En este punto habría que interpretar las disposiciones relacionadas con el ICO en relación con la Resolución de 25 de marzo de 2020, de la Secretaría de Estado de Economía y Apoyo a la Empresa, por la que se publica el Acuerdo del Consejo de Ministros de 24 de marzo de 2020, por el que se aprueban las características del primer tramo de la línea de avales del ICO para empresas y autónomos, para paliar los efectos económicos del COVID-19; y la Resolución de 10 de abril de 2020, de la Secretaría de Estado de Economía y Apoyo a la Empresa, por la que se publica el Acuerdo del Consejo de Ministros de 10 de abril de 2020, por el que se instruye al Instituto de Crédito Oficial a poner en marcha el segundo tramo de la línea de avales aprobada por el Real Decreto-ley 8/2020, de 17 de marzo, y se establece que sus beneficiarios sean las pequeñas y medianas empresas y autónomos afectados por las consecuencias económicas del COVID-19.

${ }^{13}$ Puede visitarse la página web en: https://acelerapyme.gob.es.

${ }^{14}$ Véanse las reflexiones pioneras de Gimeno Feliú ante la situación, en J.M. Gimeno Feliú, La crisis sanitaria COVID 19 y su incidencia en la contratación pública, „El Cronista del Estado Social y Democrático de Derecho" 2020, n 86-87, 2020; I. Gallego Córcoles, La formalización de contratos en tiempos de alarma: 
mos a analizar, pues han sido estudiadas con gran maestría en otros trabajos ${ }^{15}$, han ido dirigidas esencialmente a la reformulación o adaptación de las prerrogativas de reequilibrio económico del contrato, las posibles prórrogas, modificaciones del contrato, indemnizaciones, etc.

Todo lo anterior, por tanto, compone el marco principal de medidas estructurales acometidas durante el periodo del Estado de Alarma para mitigar los efectos inmediatos o a corto plazo que pudieran tener las medidas de paralización de la economía. Esto es, se trataba de medidas de contención o amortiguación. Sin embargo, es ya evidente a la fecha de finalización del presente capítulo que las secuelas económicas de la crisis sanitaria provocada por el COVID-19 se prolongarán en el tiempo y marcarán con toda seguridad el devenir económico de los diversos países en los próximos años. En el presente trabajo nos centramos, por ello, en el papel que la contratación pública puede desempeñar en la reactivación económica, y en particular, en el mantenimiento o impulso del entramado económico local que componen las pymes y los autónomos, de cuya supervivencia dependerá, en buena medida, la capacidad de ahorro y gasto, y por tanto de crecimiento, de los Estados. En este contexto, analizaremos las posibilidades y aspectos de mejora, tanto a nivel nacional como local, para conseguir que la contratación pública actúe como un elemento que participe en el renacer económico de la masa empresarial, haciendo especial énfasis en el papel que la contratación pública puede jugar como dinamizador de la digitalización empresarial de las pequeñas empresas.

\section{Herramientas directas e indirectas para la digitalización de las pymes}

Tal y como se ha expuesto en anteriores apartados, durante las últimas décadas se han tomado múltiples medidas encaminadas a conseguir una digitalización de las pymes. Así, diversos países han aprobado sistemas de bonificaciones fiscales a las inversiones en I+D, algunos de ellos, además, como el caso de España, configurados con bonificaciones muy generosas, ayudas a inversiones en conectividad para las pymes que participen en programas públicos de digitalización ${ }^{16}$. Algunas herramientas como los bonos de cuantía fija para financiar la inversión en digitalización (voucher) en Bélgica, o la creación de centros de capacidades tecnológica “Technology Center Program" en Irlanda, han sido especialmente utilizados por algunos países europeos. A esto hay que añadir las numerosas iniciativas para crear

contratos incluidos en el ámbito objetivo del recurso especial, „Observatorio de Contratación Pública”, 1 de abril de 2020; X. Lazo Vitoria, Contratación pública de emergencia COVID-19, „Observatorio de Contratación Pública", 30 de marzo de 2020.

${ }^{15}$ Véanse, por ejemplo, las contribuciones de Gimeno Feliú, Moreno Molina, Tornos Más, Lazo Vitoria o Medina Arnáiz en la monografía Observatorio de los contratos públicos 2019, dir. J.M. Gimeno Feliú.

${ }^{16}$ C. Rivas Sánchez, Los incentivos fiscales a la innovación en españa y en el ámbito comparado. "Crónica Tributaria" 2008, n 127, pp. 131-156. 
un conjunto de estrategias, programas, iniciativas, capacidades, infraestructuras y recursos que se han dado a lo largo de Europa.

Sin embargo, existen diferentes circunstancias que han hecho muy poco efectivos estos mecanismos de fomento de la inversión, que han derivado en que una parte significativa del presupuesto público destinado a subvenciones y/o préstamos para innovación no ha llegado a gastarse en los últimos años. Entre ellos, cabría destacar una excesiva burocratización del acceso a los mismos (trámites, documentación, etc.), así como la incertidumbre o falta de transparencia comunicativa acerca de no conocer con seguridad el montante final de la deducción que esta inversión podría lleva conllevar. Esto hace que en muchas ocasiones, la pequeña empresa no opte por este tipo de inversión por considerarla incierta y dificultosa. En cualquier caso, el impulso de la digitalización por pare de las pymes requiere de una estrategia multinivel, que debe abarcar también, por supuesto, la actuación en materia de contratación pública.

\section{El encaje de la digitalización de las pymes en la estrategia de contratación pública europea}

El objetivo de la contratación pública tradicional no ha sido, sin embargo, beneficiar a los empresarios en uno $\mathrm{u}$ otro modo. Al adjudicar un contrato, hay un primer objetivo que debe alcanzarse: la prestación de servicios a la Administración o a los ciudadanos. Por lo tanto, existe un grupo principal de personas interesadas que los administradores de contratos deben tener en cuenta al establecer los criterios de adjudicación. Este grupo se puede identificar con los clientes del servicio, que puede ser la propia Administración Pública o un grupo reducido de ciudadanos más o menos bien definido. Sin embargo, los objetivos actuales de contratación pública van mucho más allá de la mera oferta de bienes y servicios a un grupo determinado de clientes. La contratación pública se ha convertido en una política pública y, como tal, en un instrumento clave para el desarrollo de las sociedades de maneras diferentes que requiere, en el diseño de los criterios de contratación, la observancia de un interés más amplio que trascienda aquel de los usuarios finales del servicio.

Es el caso de la protección del medio ambiente. Hoy en día se espera que los gestores públicos incluyan en los pliegos requisitos técnicos y los criterios de adjudicación destinados a garantizar o maximizar la protección del medio ambiente. Estos requisitos no se basan en un beneficio directo para los usuarios finales del servicio, sino más bien en un beneficio indirecto y más abstracto para un grupo más amplio de ciudadanos que a menudo identifica con "la sociedad". Consecuencias similares se derivan de la utilización de medidas sociales en los procedimientos de contratación pública. Algunas de las medidas concebibles, como los criterios relacionados con condiciones laborales, responden a los intereses de quienes participan 
en la prestación de servicios (trabajadores), pero otras potenciales cláusulas sociales potenciales - como las relacionadas con la inclusión de grupos desfavorecidos en el mercado laboral o disposiciones para la igualdad de género real en un sector determinado - se fundamentan en intereses de grupos que de otro modo no estarían directamente afectados por el contrato.

En cuanto a las disposiciones anticorrupción, aunque se pueda argumentar que la corrupción afecta a cada contrato individualmente y que, por lo tanto, su lucha se basa en intereses puramente contractuales, lo cierto es que las estrategias de integridad actuales están legitimadas sobre el hecho de que la corrupción socava la economía y la democracia en un ámbito mucho más amplio que el del contrato. Esto explica que incluso si el empleado público puede probar que la corrupción en un escenario determinado puede de hecho beneficiar a los usuarios finales del servicio, esto no legitima su acción, ya que hay intereses extracontractuales más amplios que deben ser protegidos ${ }^{17}$.

Por último, debemos reconocer que, aunque el objetivo principal de la contratación pública no es beneficiar a las empresas, este es sin duda uno de sus efectos. Dado que, irremediablemente, se adjudicará el contrato a uno de los licitadores, se produce una cierta preocupación sobre las consecuencias de una adjudicación, no ya para los usuarios finales y la calidad de la prestación de servicios, sino para el sistema económico en el que la empresa está impregnada, o en última instancia, para la propia empresa ${ }^{18}$. La adjudicación del contrato a una empresa determinada establecida en una región concreta, o en unas condiciones determinadas, beneficia o condiciona sin duda a la economía de ese territorio. Las empresas son, en este punto, uno de los intereses que intervienen en el proceso de toma de decisiones, y desempeña un papel claro a la hora de evaluar el interés público del contrato.

De esta manera, aunque es cierto que la contratación pública debe dirigirse hacia la mayor eficiencia, no debemos olvidar que ésta debe tener como fin último prestar mejores servicios a los ciudadanos en aras del interés general, que es mucho más amplio que el objeto del contrato en sentido estricto ${ }^{19}$. Los contratos públicos, como política pública que "de facto" son, deben perseguir la satisfacción del interés general, el cual transciende el propio contrato y la tradicional relación bilateral contractual ${ }^{20}$. El Sector Público deja de ser un prestador de servicios directo para adquirir un

${ }^{17}$ J. Miranzo Díaz, Causas y efectos de la corrupción en las sociedades democráticas, „Revista de la Escuela Jacobea de Posgrado 2018, n 14, 2018, pp. 1-26.

${ }^{18}$ Estos efectos son analizados con mayor detalle en J. Miranzo Díaz, The tension between global public procurement law and nationalist/populist tendencies: proposals for reform, „Revista de Investigações Constitucionais" 2020, vol. 7, n 2, pp. 355-400.

${ }^{19}$ R. Medeiros, A nova Diretiva 2014/24/UE: uma primera aproximasao. R. Medeiros, L. Valadares Tavares, D. Coelho, A Nova Diretiva 2014/24/UE sobre os processos de aquisição de bens, serviços e obras baseados em contratos públicos, „Official Journal of the European Union” 2014, pp. 45-47.

${ }^{20}$ C. Barnard, To Boldly Go: Social Clauses in Public Procurement. „Industrial Law Journal” 2017, vol. $46, \mathrm{n}^{\circ} 2$, pp. $208-244$. 
nuevo rol estratégico, y esta nueva función debe llevarse a cabo haciendo uso de una ponderación de intereses que, al igual que sucede en escenarios de prestación directa de servicios por la Administración, trasciende el mero contrato y la relación clientelar empresarial ${ }^{21}$. A través de la contratación pública se debe intentar proveer de bienes y servicios a la sociedad en una forma que permita, por un lado, al sector privado alcanzar sus objetivos económicos sin dinamitar la competencia, y por otro, alcanzar mayores niveles de desarrollo a niveles más amplios ${ }^{22}$.

Y dentro de este ámbito objeto de ponderación, esto es, el entramado económico-empresarial y los efectos de la contratación en su desarrollo, es innegable el papel estratégico de la digitalización que se ha puesto de manifiesto en las páginas anteriores. Es de destacar, en este sentido, la interpelación directa que hace la Comisión Europea en su Comunicación Un nuevo modelo de industria para Europa (2020) al instar a que Estados miembros, las regiones, la industria y todas las demás partes pertinentes colaboren para crear mercados líderes en tecnologías limpias y garantizar que nuestra industria sea líder mundial, estableciendo la contratación pública, la competencia leal y la plena participación de las pymes como elementos esenciales para ello ${ }^{23}$. En esta misma línea, la European Digital SME Alliance llama a la colaboración público-privada integral como herramienta fundamental para invertir en programas de re-cualificación en tecnologías digitales y alfabetización digital, especialmente para los desempleados o aquellos en riesgo de desempleo debido a COVID-19.

\section{La incorporación de las pymes en la contratación pública de innovación}

En este punto del trabajo, es innegable que el reto de la economía europea sigue siendo incrementar la inversión pública y privada en I+D+I, especialmente en aquellos países que se encuentran con un grado menor de desarrollo, tal y como recoge el Plan Estratégico Horizonte Europa (2021-2024) que establece orientaciones estratégicas clave para el apoyo a la investigación y la innovación, adoptado el 15 de marzo de $2021^{24}$, para garantizar el crecimiento económico e impulsar la competitividad y la productividad del pais y de la UE en su conjunto. En este sentido, diversos estudios han puesto de manifiesto cómo el uso de la demanda del sector público para des-

${ }^{21}$ I. Diz, Las cláusulas sociales en la contratación pública: ¿Escudo contra los recortes de derechos sociales?. „Revista Española de Sociología” 2017, n²6, pp. 77-95.

22 J.M. Gimeno Feliú, La visión estratégica en la contratación pública en la LCSP: hacia una contratación socialmente responsable y de calidad, „Revista Economía Industrial” 2020, n 415, pp. 89-97, en p. 90.

${ }^{23}$ Comunicación de la Comisión al Consejo, al Parlamento Europeo, al Comité Económico y Social Europeo y al Comité de las Regiones de 10 de marzo de 2020, Un nuevo modelo de industria para Europa, $\operatorname{COM}(2020) 102$ final.

${ }^{24}$ Puede consultarse la nota de prensa en: https://ec.europa.eu/commission/presscorner/detail/en/ IP_21_1122. 
encadenar la innovación del sector privado es cada vez más importante y relevante para la política de innovación y como medio para apoyar las innovaciones de las PYME $^{25}$. Esto, a su vez, puede canalizarse de la siguiente manera:

\subsection{Desde el propio diseño de los contratos}

En este marco, la propia estrategia de gasto en comprar pública puede favorecer o entorpecer el desarrollo de las pymes. Así, podemos hablar de las relaciones entre innovación tecnológica y contratación también desde la perspectiva del papel que desempeña la contratación pública como agente dinamizador de la innovación ${ }^{26}$; el diseño del objeto del contrato, la elección del proyecto o necesidad a cubrir y sus características, pueden suponer un elemento determinante. Así, por ejemplo, invertir en infraestructuras de Internet en zonas rurales o más periféricas y regiones favorecerá el desarrollo tecnológico de las pequeñas empresas, pues la infraestructura es la condición básica necesaria para la digitalización y muchos países/regiones de Europa están rezagados con respecto a otras regiones mundiales a este respecto, como la realización de proyectos clave de infraestructuras de la Red Transeuropea de Transportes (RTE-T) y el despliegue de internet de alta velocidad en toda la UE. Del mismo modo sucede con el desarrollo de programas de re-cualificación en tecnologías digitales y alfabetización digital, especialmente para los desempleados o aquellos en riesgo de desempleo debido a COVID-19, que pueden favorecer la empleabilidad de las personas, pero también la digitalización de aquellas empresas en las que trabajen en el futuro.

Por otro lado, se debe potenciar lo que tradicionalmente se ha entendido como Compra pública de Innovación (CPI), esto es, aquella en la que se abre un procedimiento para desarrollar un producto que no existe en el momento en que se abre la convocatoria, pero el cual podría desarrollarse dentro de un período de tiempo razonable ${ }^{27}$. Dentro de la CPI, a su vez, encontramos la a compra pública pre-comercial (CPP) en la que se adquieren resultados de investigación esperados, y confina la financiación de actividades de I+D; (2) la CPI adaptativa, en la que el producto adquirido es nuevo en el país o región en el que se sitúa la iniciativa, y se requieren actividades de innovación para adaptar un producto ya existente a las

${ }^{25} \mathrm{~J}$. Saastamoinen, H. Reijonen, T. Tammi, Should SMEs pursue public procurement to improve innovative performance?, „Technovation” 2018, vol. 69 (C), pp. 2-14; E. Uyarra et al., Barriers to innovation through public procurement: a supplier perspective”, „Technovation” 2014, vol. 34, iss. 10, pp. 631-645; A. Talebi, D. Rezania, Governance of projects in public procurement of innovation a multi-level perspective, „Journal of Public Procurement" 2020, vol. 20, iss. 2.

${ }^{26}$ I. Gallego Córcoles, Contratación pública e innovación tecnológica, „Revista española de Derecho Administrativo" 2017, nº 184.

${ }^{27}$ J.M. Zabala-Iturriagagoitia, La Política de Compra Pública como Estímulo a la Innovación y el Emprendimiento, „Journal of Technology Management \& Innovation” 2017, vol. 12, n 1, pp. 100-108. 
particularidades de la demanda local; o (3) la CPI evolutiva conlleva el desarrollo de productos totalmente novedosos, por lo que se la relaciona con el desarrollo de innovaciones de carácter radica. A estas se podría sumar una CPI cooperativa, en la que el órgano solicitante y los proveedores cooperan durante el proceso de la compra pública. En todos estos tipos de compra pública, el modo en el que la entidad pública formula los requisitos que el nuevo producto deba cumplir tiene una influencia directa sobre el comportamiento de los potenciales proveedores ${ }^{28}$, y por tanto, su configuración debe realizarse teniendo en cuenta el acceso de las pymes a este entramado de innovación.

\subsection{El uso adecuado de procedimientos}

Por otro lado, debe fomentarse el uso de procedimientos adecuados a la innovación. Es cierto que los procedimientos ordinarios, abiertos o restringidos están en los diferentes países de la UE altamente formalizados, y no son el espacio idóneo para favorecer la innovación ${ }^{29}$. No obstante, el Derecho europeo ofrece otras herramientas y alternativas interesantes para canalizar este tipo de colaboración público-privada, que deben fomentarse en su uso diario por parte de las entidades adjudicadoras.

Estamos hablando, esencialmente, del procedimiento negociado, del procedimiento de diálogo competitivo y del de asociación para la innovación, pero no exclusivamente $^{30}$. Así, en determinados casos, como en la compra pública pre-comercial, se deberá realizar una inversión por parte de la Administración en $\mathrm{I}+\mathrm{D}$ que no se recoge en ninguno de los procedimientos de la Directiva 2014/24/UE - aunque sí que deberá, en todo caso, respetar los principios de las directivas de contratación. En este modelo, la Administración no se reserva los resultados de la I+D para su propio uso en exclusiva, sino que comparte los riesgos y beneficios con las empresas. Los modelos de asociación para la innovación, por el contrario, buscan contratar todo el proceso de innovación, desde la investigación hasta la explotación comercial y compra del nuevo producto o servicio (cuando estas soluciones no estén disponibles en el mercado, artículo 31 de la Directiva 2014/24/UE) ${ }^{31}$.

${ }^{28}$ J.M. Zabala-Iturriagagoitia, op. cit.

${ }^{29}$ I. Gallego Córcoles, Contratación pública...

${ }^{30}$ Para más detalle al respecto, véase C. De Guerrero Manso, Los tres procedimientos de asociación para la innovación licitados en España: valoración de sus aspectos clave y pros y contras de cada uno de ellos, en Observatorio de los Contratos Públicos 2018, dir. J.M. Gimeno Feliú, Pamplona 2019, pp. 281-327; y C. De Guerrero Manso, La asociación para la innovación: Nuevo procedimiento de adjudicación que permite a los órganos de contratación ser protagonistas del proceso de adquisición de bienes, servicios u obras innovadoras, en Transparencia, innovación y buen gobierno en la contratación pública, dir. M. Fernández Salmerón, R. Martínez Gutiérrez, Tirant Lo Blanch 2018, pp. 271-304.

${ }^{31}$ P. Valcárcel Fernández, La innovación como objeto prestacional en los contratos del sector público. La Compra Pública de Innovación, „Contratación administrativa práctica: revista de la contratación administrativa y de los contratistas" $2018, \mathrm{n}^{\circ} 153$, pp. 56-68. 
En un segundo estadio encontramos el diálogo competitivo y las consultas preliminares al mercado. Estos procedimientos no pretenden desarrollar un proyecto completo de innovación, pero sí desarrollar, adaptar o en encontrar nuevas soluciones con el mercado. En el diálogo competitivo el procedimiento de compra se desarrolla en dos fases, una primera en la que se negocia una solución o un objeto determinado del contrato, y una segunda en la que se produce la concurrencia en sentido estricto. Las consultas preliminares de mercado, por su parte, tratan de concretar, por parte de la Administración, cuál es el estado de desarrollo, el precio o las condiciones de un determinado servicio o bien en el mercado.

El uso de este tipo de procedimientos se ha impulsado por parte de las diferentes instituciones europeas y nacionales, pero lo cierto es que su diseño y utilización por parte de las Administraciones Públicas no se ha tenido en cuenta el posible papel que pueden desempeñar las pymes también en este tipo de procedimientos si se diseñan de la forma adecuada. Existen, no obstante, honrosas excepciones, y podemos citar ejemplos como la experiencia de Galicia (región española), en las que la aprobación de las directivas de contratación pública en 2014 que permitían una gama más amplia y flexible de procedimientos, hizo posible la creación de un proyecto de contratación pública de innovación multinivel en el sector salud, que utilizó estos procedimientos más flexibles a tal efecto, y en el que un buen porcentaje de los adjudicatarios resultaron ser pymes regionales ${ }^{32}$.

\subsection{División por Lotes (también en innovación)}

Se debe facilitar el acceso de las pymes a la contratación pública en sectores de IT o servicios digitales. DIGITAL SME y otras plataformas ha recopilado soluciones digitales proporcionadas por pymes con sede en Europa, que se extienden al teletrabajo, soluciones de salud electrónica, etc. Existe toda una red de proveedores digitales de pequeño tamaño, a los cuales se les debe garantizar el acceso a la contratación pública. Además, a nivel europeo, en este tipo de contratos, el fomento de la participación de las pymes puede ser más efectivo, ya este tipo de servicios no requerirán, como norma general, desplazamientos o prestaciones de servicios en un país extranjero que en ocasiones funcionan como desincentivo para que las pymes europeas se embarquen en licitaciones transnacionales ${ }^{33}$. Apoyar las estrategias de innovación y competitividad empresarial desarrolladas por estos colectivos o "clusters" de empresas, generalmente pymes, es fundamental.

${ }^{32}$ Véase la experiencia analizada en E. Uyarra, J. Edler, S. Gee, L. Georghiou, J. Yeow, Public procurement for innovation: the UK case, en L. Lember, T. Kalvet, R. Kattel (Eds.), Public Procurement Policy for Innovation: International Perspectives, New York 2013, pp. 233-257.

${ }^{33}$ J.M. Zabala-Iturriagagoitia, op. cit. 
Para este objetivo, la división en lotes de los contratos se ha demostrado una herramienta fundamental. La Directiva 2014/24, que regula los contratos públicos por encima de los umbrales europeos y armoniza las normativas nacionales de los Estados Miembros, regula la división del objeto de contrato en lotes en su artículo 46, y parece invertir esta tendencia existente en el derecho español ${ }^{34}$. En él, el regulador europeo no establece de manera directa una obligación de dividir ${ }^{35}$-como sí hace el legislador español en el artículo 99.3 de la LCSP de 2017-, pero sí que introduce una nueva regla que en la doctrina jurídica europea se ha identificado como "explain or divide" (explica o divide) ${ }^{36}$, que impone la obligación a las entidades adjudicadoras de motivar y justificar su decisión en caso de no dividir el contrato ${ }^{37}$. Algunos autores europeos han entendido esta cuestión como un requerimiento débil, que exige explicación, pero no necesariamente de justificación - al menos desde la perspectiva de la Directiva 2014/24 -, de forma que esta "explicación” estaría únicamente sujeta a revisión judicial leve ${ }^{38}$. Lo que el legislador europeo está exigiendo es, por tanto, que el poder adjudicador considere la posibilidad de dividir en lotes $^{39}$, convirtiendo en la práctica la división en la opción predeterminada ${ }^{40}$.

En cualquier caso, este mecanismo de fomento de pymes, el principal de la normativa europea, no está siendo utilizado suficientemente en sectores relacionados con la digitalización. Existe una cierta tendencia a contratar servicios de software con grandes compañías digitales, pero lo cierto es que existe un buen número de startups en el ámbito de los servicios electrónicos. Los grandes contratos, por su capacidad y volumen, suponen una barrera de entrada para estas empresas digitales de pequeño tamaño. Esta realidad responde a diferentes factores jurídicos que hacen

${ }^{34}$ E. Candela Talavero, Objeto del contrato público y su división. „Gabilex” 2019, 18, pp. 15-69.

${ }^{35}$ M.A. Raimundo, Aiming at the Market You Want. A critical Analysis of the Duties on Division into Lots under Direcive 2014/24/EU, „Public Procurement Law Review 2018, nº 4, pp. 167 y ss; M.C. Rodríguez Martín-Retortillo, Fraccionamiento del contrato y división en lotes. Posibilidad de limitar el número de lotes a los que un operador económico pueda licitar o adjudicarse a cada licitador, „Anuario da Facultade de Dereito da Universidade da Coruña" 2017, n² 21, pp. 192-228.

${ }^{36}$ M. Trybus, The Division of Public Contracts into Lots under Directive 2014/24, „European Law Review”, 2018, vol. 43, n 3, pp. 313-342; M.A. Raimundo, op. cit.; B. Gómez Fariñas, op. cit.

37 "El apartado 1 del artículo 46 de la nueva Directiva de contratación pública no impone a los poderes adjudicadores la obligación de dividir los contratos en lotes, sino tan solo la de motivar la decisión de no efectuar dicha división, en los pliegos o en el informe específico al que se refiere el artículo 84 de la Directiva". TACRC, Resolución 387/2018, de 23 de abril.

38 M. Trybus, op. cit., p. 328; I. Herrera Anchustegui, Division into Lots and Demand Aggregation - Extremes Looking for the Correct Balance?, en Reformation or Deformation of the EU Public Procurement Rules in 2014, dir. G.S. Ølykke, A. Sánchez Graells, Cheltenham 2016; algunos autores incluso han sostenido la no sujeción de estos aspectos al control jurisdiccional, véase A. Sánchez Graells, Public Procurement and the EU Competition Rules, Hart 2015.

${ }^{39}$ Resolución 318/2016, de 7 de diciembre de 2016, Tribunal de Andalucía. En el mismo sentido, A. Sánchez Graells, op. cit., p. 347.

${ }^{40}$ M.A. Raimundo, op. cit., p. 167 y ss. 
especialmente laxa la obligación de dividir en lotes, especialmente en contratos de innovación o relacionados con las tecnologías digitales.

En primer lugar, el órgano de contratación goza de un amplio margen de discrecionalidad técnica para determinar el objeto del contrato y su división o no en lotes, debiendo, eso sî, explicar las razones principales por las cuales decide que no procede dicha división, razones que han de atender a un motivo válido, es decir, que no resulte arbitrario ni contrario a la finalidad última del precepto: la concurrencia de las pymes (TACRC, Resolución 981/2018, de 26 de octubre; Resolución 993/2018, de 2 de noviembre; Resolución 1026/2018, de 13 de noviembre y 430/2018) ${ }^{41}$.

En todo caso, la decisión de no dividir y las motivaciones que lo sustentan, deben ser suficientes, y por tanto son evaluadas bajo el prisma del test de proporcionali$\mathrm{dad}^{42}$. Y en este sentido, la justificación de la agrupación de lotes o la no división no puede venir determinada por cuestiones generales, abstractas o vagas, sino por criterios relevantes y ciertos ${ }^{43}$. A modo de ejemplo, el Tribunal Administrativo de Contratación Pública de la Comunidad de Madrid señala en su Resolución 75/2018, de 14 de marzo, que la existencia de una central de compras que gestiona el contrato no es suficiente para una no división, ya que la racionalización de una Central de Compras no está reñida con la posibilidad de división en lotes. Y del mismo modo, tampoco es justificación suficiente la existencia de un contrato anterior con las mismas características.

Asimismo, el TJUE ha configurado algunos elementos de la motivación de no dividir. Así, el TJUE, en el asunto C-145/08 Club Hotel Loutraki y otros, de 6 de mayo de 2010, señala que "en el caso de un contrato mixto cuyas distintas estipulaciones están ligadas inseparablemente y forman, por lo tanto, un todo indivisible -con arreglo a lo indicado en el anuncio de licitación-, la operación en cuestión debe examinarse en su conjunto de forma unitaria", y por tanto esta conexión entre tipos contractuales viene aceptándose como elemento justificación por los tribunales nacionales (Tribunal Administrativo Central de Recursos Contractuales, resolución 625/2019, de 6 de junio), si bien, como se ha encargado de matizar la Junta Consultiva de Contratación Pública del Estado, ello no impide que los contratos mixtos puedan dividirse en lotes para cada una de las prestaciones (Informe 7/2019).

En todo caso, aunque es cierto que la norma y tribunales han venido exigiendo que los motivos que justifiquen la no división sean concretos, válidos y claros, lo cierto es que en ocasiones ha desarrollado una labor interpretativa ciertamente creativa para aceptar justificaciones que, a primera vista, parecían no imbuirse

${ }^{41}$ J. Miranzo Díaz, La exigencia de la división en lotes como garantía de acceso de las pymes al mercado de la contratación pública, en Inclusión de cláusulas sociales y medioambientales en los pliegos de contratos públicos, dir. A. Sánchez García, M. Pardo López, Pamplona 2020, pp. 163-180.

${ }^{42}$ M.A. Raimundo, op. cit., p. 167 y ss.

${ }^{43}$ J.M. Martínez Fernández, Medidas para facilitar a las PYMEs la participación en la contratación pública, „Contratación administrativa práctica” 2018, n 153, pp. 94-103. 
dentro de los requisitos expuestos. Así, en su Resolución 981/2018, el Tribunal español aceptó una justificación que extraía de forma literal parte del artículo 99 de la Ley de Contratos del Sector Público al entender que "si bien es cierto que en el presente caso en el cuadro de caracterîsticas de los pliegos las razones para la no división en lotes no se encontraban justificadas, más allá de marcar una casilla con una explicación absolutamente genérica, analizada la documentación del expediente y en concreto la memoria justificativa del mismo, se observa que sî existe una razón técnica perfectamente justificada que explica la decisión de no dividir en lotes y que se encuentra en el origen mismo de esta licitación" ${ }^{44}$.

Por último, conviene mencionar que, si bien existe una obligación de motivar en los términos que se han expresado, la ausencia de dicha motivación en los pliegos o en el expediente del contrato no afecta a la validez de los mismos ${ }^{45}$ - siempre y cuando el fondo de la controversia, es decir, la justificación o motivación en sí misma, esté justificada -, ya que la misma es considerada un error de forma o de procedimiento que no cumple con los requisitos recogidos por artículo 47.1.e) la LPAC para apreciar nulidad de pleno derecho. Así lo ha afirmado el TACRC en su resolución 230/2018, que se apoya en la jurisprudencia del Tribunal Supremo, concretamente en la STS 230/2018, de 4 de abril, en la que el Alto tribunal afirma que:

"[...] resulta evidente que, si lo que integra el fondo mismo de la cuestión principal, es decir, la liquidación del Impuesto controvertido, ha de ser objeto de una solución jurisdiccional en cierto modo [...], carece de sentido y toda justificación práctico-jurîdica decretar la nulidad de actuaciones pretendida por la recurrente [...] por no haberse producido, en definitiva, la indefensión de nadie y porque, en cualquier caso, la anulación de lo actuado a partir de la omisión inicial sólo implicará una reiteración del procedimiento para llegar a una conclusión material o de fondo de igual tenor a la que se ha de dejar plasmada en esta sentencia”.

Es por tanto el fondo, es decir, si la división en lotes está o no justificada, y no el elemento formal de la inclusión de la motivación en el expediente, lo que determina la validez o invalidez de las actuaciones (en el mismo sentido pueden verse las Resolución 387/2018, de 23 de abril, del TACRC).

Toda esta configuración jurídica deriva en que, a pesar de esta obligación general de división en lotes, y del aparente control jurisdiccional ejercido por los tribunales, el margen de discrecionalidad aceptado por los tribunales es notablemente amplio. Esto, único a la falta de efectos invalidantes de la ausencia de justificación expresa, hacen que el correcto uso de la división en lotes como herramienta dependa casi exclusivamente de la voluntad política o administrativa que tenga un carácter estratégico. Es fundamental, por tanto, la labor de difusión, educación y formación de

${ }^{44}$ El mismo argumento interpretativo ha sido usado en otras resoluciones, como la Resolución 993/2018, de 2 de noviembre.

${ }^{45}$ E. Candela Talavero, op. cit., pp. 15-69. 
los empleados y las entidades adjudicadoras para inculcar una verdadera conciencia sobre la relevancia capital del uso de la división por lotes en contratos de prestación de servicios de IT o de digitalización de los servicios de la Administración.

\subsection{Posibilidad de incluir cláusulas de innovación en los contratos}

Por último, debe potenciarse la inclusión cláusulas de ejecución carácter innovador o tecnológico también en contratos ordinarios en los que participen pymes ${ }^{46}$. La propia Directiva 2014/24/UE prevé que los poderes adjudicadores podrán establecer condiciones especiales de innovación relativas a la ejecución del contrato, siempre que estén vinculadas al objeto del contrato y se indiquen en la convocatoria de la licitación o en los pliegos de la contratación (artículo 70).

Estas cuestiones, por tanto, no puede afectar al global de la empresa y deberán ir dirigidas al objeto del contrato. Sin embargo, esta limitación no debe servir para renunciar a incluir este tipo de cláusulas de innovación o de digitalización en el funcionamiento de la empresa adjudicataria. Debemos tener en cuenta que este límite relativo a las condiciones que se pueden incluir que no afecten a la organización empresarial se ha moldeado de una forma cada vez más difusa o líquida por al jurisprudencia. Se han aceptado criterios en relación a la inclusión social en los empleados contratados, implantación de estrategias de género, implantación de mecanismos de compliance, sistemas de gestión ambiental, etc. Todos ellos se encuentran aplicados al contrato, sí, pero en la práctica son elementos que, al aplicarse al contrato, terminarán afectando al funcionamiento global de la empresa, y lo que es más, en muchos casos no evidencian una repercusión directa en la calidad, el precio o la eficiencia en el producto o servicio final del contrato. Por el contrario, aquellos elementos relacionados con la digitalización o la innovación en terminados aspectos organizacionales, y siempre que se circunscriba su aplicación al objeto del contrato, pueden incidir muy positivamente en la eficiencia de la empresa en su desempeño, y por tanto, en la calidad final de la prestación del servicio o ejecución del contrato.

En este sentido, podemos pensar en elementos como la implantación de factura electrónica, venta online, herramientas de gestión empresarial digitales, equipamiento técnico, infraestructuras y tecnología (Cloud, el Bigdata y la IA), cambio cultural, organización y comunicación; capacitación del personal, del empresario y del equipo directivo, desarrollo de competencias digitales; rediseño de procesos internos de la empresa para automatizarlos y aumentar la eficiencia y la productividad, etc. Todos ellos pueden repercutir directamente en la forma y la eficiencia con la que la empresa ejecuta el contrato. Del mismo modo, la adopción de tecnologías de IA comporta una transformación profunda de las empresas, no solo a nivel de

${ }^{46}$ I. Gallego Córcoles, La integración de cláusulas sociales, ambientales y de innovación en la contratación pública, „Documentación Administrativa. Nueva Época” 2017, n 4, pp. 92-113. 
sus infraestructuras o procesos tecnológicos, sino también a nivel de organización y estrategia, que puede tener importantes ahorros tanto para la Administración contratante como para la empresa en última instancia.

\section{Conclusiones}

En definitiva, tras lo expuesto en el presente trabajo se ha puesto de manifiesto cómo la promoción de las pymes a través de la contratación pública y el fomento de la innovación tecnológica pueden - y deben - ir de la mano. La contratación pública tradicional a menudo obviaba la importancia de estas dos funciones estratégicas de esta actividad del sector público. La apuesta por una contratación pública estratégica, especialmente tras la aprobación del paquete de directivas de 2014, impulsó la inclusión de este tipo de cláusulas, y un abanico de nuevos procedimientos y medidas que garantizaban, de un lado, la inclusión de las pymes, y de otro, la innovación tecnológica. Estas nuevas líneas estratégicas fueron acogidas con desigual entusiasmo por las Administraciones Públicas, pero gradualmente el cambio de paradigma ha ido operando en los diferentes niveles de actuación pública.

Ahora, ha llegado el momento de entender la implantación de líneas estratégicas desde una prospectiva global, entendiéndolas como lo que son, elementos interconectados que deben implantarse y aplicarse en todas las capas de la contratación pública de forma conjunta, a través de una debida ponderación de intereses públicos y de un adecuado diseño técnico de los contratos. Tras la crisis provocada por la COVID-19 y su especial incidencia en las pequeñas empresas, se ha puesto de relieve la necesidad de impulsar la digitalización de este sector productivo capital en Europa. De este modo, la contratación pública no sólo debe abrirse a la participación de pequeñas empresas y fomentar su consolidación económica, sino también promover su digitalización y su participación en los procesos de innovación tecnológica. En el presente trabajo se ha puesto de manifiesto cómo actualmente existen diferentes estrategias de ámbitos de actuación que deben abordarse para la consecución de este objetivo.

\section{Streszczenie / Resumen extenso}

Zamówienia publiczne jako instrument cyfryzacji MŚP

Znaczenie małych i średnich przedsiębiorstw (MŚP) dla struktury społecznej i gospodarczej Unii Europejskiej jest niezaprzeczalne. Jak stwierdza Komisja Europejska, stanowią one ponad $99 \%$ wszystkich firm europejskich. W ramach wzmacniania pozycji gospodarczej i kwalifikacji MŚP cyfryzacja stała się kluczowym elementem. 
W European Innovation Scoreboard 2020 zarówno Hiszpania, jak i Polska zostały zaklasyfikowane $w$ ramach kategoryzacji stworzonej przez UE jako „umiarkowani innowatorzy" wraz z innymi krajami takimi jak Włochy, Grecja, Czechy, Słowacja i Węgry. W tej sytuacji cyfryzacja MŚP jest od lat jedną z głównych osi działań UE w jej strategii rozwoju, choć być może stała się ona szczególnie widoczna po kryzysie wywołanym przez COVID-19. Wszystkie podmioty gospodarcze odczuły te konsekwencje, ale MŚP i osoby samozatrudnione, właśnie ze względu na ograniczony budżet i brak płynności finansowej, były szczególnie narażone i podatne na te nadzwyczajne wydatki (a raczej na brak dochodów).

Trudności w podejmowaniu działań oraz konieczność przetrwania przez MŚP kryzysu gospodarczego wynikającego z sytuacji zdrowotnej sprawiły, że $48 \%$ takich przedsiębiorstw $\mathrm{z}$ powodu kryzysu zainwestowało $\mathrm{w}$ oprogramowanie, zmieniając swój plan inwestycji w oprogramowanie obowiązujący od początku pandemii. W tym kontekście Komisja Europejska powtórzyła, że cyfryzacja i wdrażanie narzędzi sztucznej inteligencji (SI [AI]) powinny być traktowane jako jeden z filarów rozwoju, a wzrost zdolności technologicznej i dostępności danych, a także postępy w dziedzinie algorytmów sprawiły, że SI [AI] i narzędzia cyfrowe stały się jedną $\mathrm{z}$ najbardziej strategicznych technologii XXI wieku ${ }^{47}$.

Mimo że przynoszenie korzyści przedsiębiorstwom nie jest głównym celem zamówień publicznych, jest z pewnością jednym $\mathrm{z}$ ich efektów. Biorąc pod uwagę, że zamówienie zostanie nieodwołalnie udzielone jednemu z oferentów, istnieją pewne obawy co do konsekwencji udzielenia zamówienia już nie dla użytkowników końcowych i jakości świadczonych usług, ale dla systemu gospodarczego, w którym przedsiębiorstwo jest osadzone, lub ostatecznie dla samego przedsiębiorstwa ${ }^{48}$. Przedsiębiorstwa są $\mathrm{w}$ tym momencie jednym $\mathrm{z}$ podmiotów zaangażowanych w proces podejmowania decyzji i odgrywają wyraźną rolę w ocenie interesu publicznego zamówienia.

Choć oczywiste jest, że zamówienia publiczne powinny być ukierunkowane na większą efektywność, to nie powinniśmy zapominać, że ich ostatecznym celem powinno być zapewnienie lepszych usług dla obywateli w interesie ogólnym, który jest znacznie szerszy niż przedmiot zamówienia w ścisłym tego słowa znaczeniu. Zamówienia publiczne jako instrument polityki publicznej, którą de facto stanowią, muszą dążyć do zaspokojenia interesu ogólnego, który wykracza poza umowę i tradycyjny dwustronny stosunek umowny. W tym kontekście warto zwrócić uwagę na bezpośredni apel Komisji Europejskiej zawarty w jej komunikacie Nowy model przemysłu dla Europy (2020), w którym wzywa ona państwa członkowskie, regiony,

${ }^{47}$ Komunikat Komisji do Parlamentu Europejskiego, Rady Europejskiej, Europejskiego Komitetu Ekonomiczno-Społecznego i Komitetu Regionów: Sztuczna inteligencja dla Europy, COM(2018) 237 final, Bruksela 25.4.2018.

${ }^{48}$ Tego typu sytuacje są bardziej szczegółowo analizowane w: J. Miranzo Díaz, The tension between global public procurement law and nationalist/populist tendencies: proposals for reform, „Revista de Investigações Constitucionais" 2020 , vol. 7 , n 2, s. 355-400. 
przemysł i wszystkie inne zainteresowane strony do współpracy w celu budowania wiodących rynków czystych technologii i zapewnienia naszemu przemysłowi pozycji światowego lidera, uznając zamówienia publiczne, uczciwą konkurencję i pełne uczestnictwo MŚP za zasadnicze elementy tego procesu.

$\mathrm{W}$ różnych badaniach pokazano, że wykorzystanie popytu sektora publicznego w celu pobudzenia innowacji sektora prywatnego staje się coraz ważniejsze i istotniejsze jako środek wspierania innowacji MŚP, co można osiągnąć za pomocą różnych mechanizmów.

Pierwszym jest projekt umów. Sama strategia wydatkowania środków w ramach zamówień publicznych może sprzyjać rozwojowi MŚP lub utrudniać go. W tym kontekście decydującym czynnikiem projektu może być przedmiot zamówienia, wybór projektu lub potrzeby, które mają być objęte zamówieniem, oraz ich cechy. $\mathrm{Z}$ drugiej strony należy wzmacniać to, co tradycyjnie rozumie się jako zamówienia publiczne na innowacje (PPI), tj. takie, w których otwiera się postępowanie na opracowanie produktu, który nie istnieje w momencie ogłaszania zaproszenia [do składania ofert], ale który mógłby zostać opracowany w rozsądnym terminie. We wszystkich tych rodzajach zamówień publicznych sposób, $\mathrm{w}$ jaki podmiot publiczny formułuje wymagania, które musi spełniać nowy produkt, ma bezpośredni wpływ na zachowanie potencjalnych dostawcó $w^{49}$, a zatem jego konfiguracja musi uwzględniać dostęp MŚP do takiego planu innowacji.

Kolejny mechanizm to właściwe stosowanie procedur. Należy wspierać stosowanie odpowiednich procedur dla innowacji. Zasadniczo mówimy o procedurze partnerstwa dla innowacji, ale nie wyłącznie

Stosowanie tego typu procedur było promowane przez różne instytucje europejskie i krajowe, ale prawdą jest, że przy ich opracowywaniu i stosowaniu przez administracje publiczne nie uwzględniono możliwej roli, jaką również MŚP mogą odegrać w tego typu procedurach, jeśli zostaną one opracowane w odpowiedni sposób.

Mechanizmem wspierania MŚP może być również podział zamówień na części (również w zakresie innowacji). Należy ułatwić dostęp MŚP do zamówień publicznych w sektorach IT lub usług cyfrowych. DIGITAL SME i inne platformy zebrały rozwiązania cyfrowe dostarczane przez MŚP z siedzibą w Europie, obejmujące telepracę, rozwiązania w zakresie e-zdrowia itp. Istnieje cała sieć małych dostawców usług cyfrowych, którzy powinni mieć zagwarantowany dostęp do zamówień publicznych. Ponadto na poziomie europejskim w tego typu zamówieniach promowanie udziału MŚP może być bardziej skuteczne, ponieważ ten typ usług nie będzie wymagał, co do zasady, przemieszczania lub świadczenia usług za granicą, co czasami zniechęca europejskie MŚP do udziału w przetargach międzynarodowych.

Podział zamówień na części okazał się bardzo ważnym narzędziem. Jednakże taki mechanizm wspierania MŚP, będący podstawą w prawodawstwie europejskim,

\footnotetext{
${ }^{49}$ J.M. Zabala-Iturriagagoitia, dz. cyt.
} 
nie jest w wystarczającym stopniu wykorzystywany w sektorach związanych z cyfryzacją. Duże kontrakty, ze względu na swoją pojemność i wielkość, stanowią barierę wejścia dla tych małych firm cyfrowych. Konieczne jest zatem edukowanie i szkolenie pracowników i instytucji zamawiających w celu zaszczepienia świadomości istotnego znaczenia stosowania podziału na części w zamówieniach na świadczenie usług IT lub cyfryzację usług administracji publicznej.

Ostatnim mechanizmem jest możliwość włączenia do umów klauzul dotyczących innowacji. Poza tym, w zwykłych umowach z udziałem MŚP należy w większym stopniu uwzględniać klauzule dotyczące wykonania o charakterze innowacyjnym lub technologicznym. Dyrektywa 2014/24/UE stanowi, że instytucje zamawiające mogą określić szczególne warunki innowacyjności dotyczące realizacji zamówienia, pod warunkiem że są one związane z przedmiotem zamówienia i zostały wskazane w zaproszeniu do składania ofert lub w specyfikacji dotyczącej zamówienia (art. 70). Te elementy związane z cyfryzacją lub innowacją w niektórych aspektach organizacyjnych, pod warunkiem że ich zastosowanie ogranicza się do przedmiotu zamówienia, mogą mieć bardzo pozytywny wpływ na wydajność przedsiębiorstwa, a tym samym na ostateczną jakość świadczenia usług lub wykonania zamówienia.

Niniejsze opracowanie pokazuje, w jaki sposób promowanie MŚP poprzez zamówienia publiczne oraz rozwój innowacji technologicznych mogą - i powinny - iść w parze. Zaangażowanie w strategiczne zamówienia publiczne, zwłaszcza po zatwierdzeniu pakietu dyrektyw z 2014 roku, przyczyniło się do włączenia tego rodzaju klauzul oraz licznych nowych procedur i środków, które zapewniły z jednej strony włączenie MŚP, a z drugiej - innowacje technologiczne. Obecnie nadszedł czas, aby zrozumieć wdrażanie linii strategicznych z perspektywy globalnej, rozumiejąc je jako wzajemnie powiązane elementy, które muszą być wdrożone i stosowane na wszystkich szczeblach zamówień publicznych jako całości, poprzez należyte oszacowanie interesów publicznych i odpowiednie opracowanie techniczne umów. W następstwie kryzysu spowodowanego przez COVID-19 i jego szczególnego wpływu na małe przedsiębiorstwa podkreślono potrzebę pobudzenia cyfryzacji tego kluczowego sektora produkcji w Europie. Dlatego też zamówienia publiczne powinny nie tylko otwierać się na udział małych przedsiębiorstw i zachęcać je do konsolidacji gospodarczej, ale także promować ich cyfryzację i udział w procesach innowacji technologicznych. W niniejszym opracowaniu pokazano, że obecnie istnieją różne strategie i obszary działania, którymi należy się zająć, aby osiągnąć ten cel.

\section{Bibliografía}

Barnard C., To Boldly Go: Social Clauses in Public Procurement, „Industrial Law Journal” 2017, vol. 46, no 2, pp. 208-244.

Candela Talavero E., Objeto del contrato público y su división, „Gabilex” 2019, n¹8, pp. 15-69. 
Comunicación de la Comisión al Consejo, al Parlamento Europeo, al Comité Económico y Social Europeo y al Comité de las Regiones de 10 de marzo de 2020, Un nuevo modelo de industria para Europa, $\operatorname{COM}(2020) 102$ final.

Comunicación de la Comisión al Parlamento Europeo, al Consejo Europeo, al Consejo, al Comité Económico y Social Europeo y al Comité de las Regiones, de 25 de abril de 2018, Inteligencia artificial para Europa, $\operatorname{COM}(2018) 237$ final.

De Guerrero Manso C., La asociación para la innovación: Nuevo procedimiento de adjudicación que permite a los órganos de contratación ser protagonistas del proceso de adquisición de bienes, servicios u obras innovadoras, en Transparencia, innovación y buen gobierno en la contratación pública, dir. M. Fernández Salmerón, R. Martínez Gutiérrez,Tirant Lo Blanch 2018, pp. 271-304.

De Guerrero Manso C., Los tres procedimientos de asociación para la innovación licitados en España: valoración de sus aspectos clave y pros y contras de cada uno de ellos, en Observatorio de los contratos públicos 2018, dir. J.M. Gimeno Feliú, Pamplona 2019, pp. 281-327.

De Guerrero Manso C., ¿Compara Pública de innovación en tiempo de COVID-19?, en Observatorio de los contratos públicos 2019, dir. J.M. Gimeno Feliú, Pamplona 2020, pp. 433-458.

Dirección General de Politica de la Pequeña y Mediana Empresa. Análisis sectorial de implantación de las tic en la pyme española, 2011.

Diz I., Las cláusulas sociales en la contratación pública: ¿Escudo contra los recortes de derechos sociales?, „Revista Española de Sociología” 2017, n² 26, pp. 77-95.

European Digital SME Alliance, Position paper on the Digital Services Act (DSA), 8 September 2020.

Gallego Córcoles I., Contratación pública e innovación tecnológica, „Revista española de Derecho Administrativo" 2017, n 184.

Gallego Córcoles I., La formalización de contratos en tiempos de alarma: contratos incluidos en el ámbito objetivo del recurso especial, Observatorio de Contratación Pública, 1 de abril de 2020.

Gallego Córcoles I., La integración de cláusulas sociales, ambientales y de innovación en la contratación pública, „Documentación Administrativa. Nueva Época” 2017, n 4, pp. 92-113.

Gimeno Feliú J.M., La crisis sanitaria COVID 19 y su incidencia en la contratación pública, „El Cronista del Estado Social y Democrático de Derecho" 2020, nº 86-87.

Gimeno Feliú J.M., La visión estratégica en la contratación pública en la LCSP: hacia una contratación socialmente responsable y de calidad, „Revista Economía Industrial” 2020, n 415, pp. 89-97.

Gobierno de España. Plan de Digitalización Pymes 2021-2025, 2021.

Gómez Fariñas B., La participación de las PYMES en la contratación pública: una visión desde el derecho europeo, „Revista Digital de Derecho Administrativo” 2020, n² 24, pp. 161-182.

Herrera Anchustegui I., Division into Lots and Demand Aggregation - Extremes Looking for the Correct Balance?, en Reformation or Deformation of the EU Public Procurement Rules in 2014, dir. G.S. Ølykke, A. Sánchez Graells, Cheltenham 2016.

Lazo Vitoria X., Contratación pública de emergencia COVID-19, „Observatorio de Contratación Pública", 30 de marzo de 2020.

Martínez Fernández J.M., Medidas para facilitar a las Pymes la participación en la contratación pública, „Contratación administrativa práctica” 2018, n 153, pp. 94-103.

Medeiros R., A nova Diretiva 2014/24/UE: uma primeira aproximasao, en R. Medeiros, L. Valadares Tavares, D. Coelho (dir.), A Nova Diretiva 2014/24/UE sobre os processos de aquisição de bens, serviços e obras baseados em contratos públicos, „Official Journal of the European Union” 2014, pp. 45-47.

Miranzo Díaz J., Causas y efectos de la corrupción en las sociedades democráticas, „Revista de la Escuela Jacobea de Posgrado" 2018, n 14, pp. 1-26.

Miranzo Díaz J., La exigencia de la división en lotes como garantîa de acceso de las PYMES al mercado de la contratación pública, en Inclusión de cláusulas sociales y medioambientales en los pliegos de contratos públicos, dir. A. Sánchez García, M. Pardo López, Pamplona 2020, pp. 163-180. 
Miranzo Díaz J., The tension between global public procurement law and nationalist/populist tendencies: proposals for reform, „Revista de Investigações Constitucionais” 2020, vol. 7, n² 2, pp. 355-400.

Molero, J. et. al. Pymes y COVID-19: hacia una recuperación sostenible, Red Española del Pacto Mundial 2020.

Observatorio de los contratos públicos 2019, dir. J.M. Gimeno Feliú, Pamplona 2020.

Raimundo M.A., Aiming at the Market You Want. A critical Analysis of the Duties on Division into Lots under Direcive 2014/24/EU, „Public Procurement Law Review” 2018, n² 4, pp. 167 y ss.

Rivas Sánchez C., Los incentivos fiscales a la innovación en españa y en el ámbito comparado, „Crónica Tributaria" 2008, no 127, pp. 131-156.

Rodríguez Martîn-Retortillo M.C., Fraccionamiento del contrato y división en lotes. Posibilidad de limitar el número de lotes a los que un operador económico pueda licitar o adjudicarse a cada licitador, „Anuario da Facultade de Dereito da Universidade da Coruña” 2017, n² 21, pp. 192-228.

Saastamoinen J., Reijonen H., Tammi T., Should SMEs pursue public procurement to improve innovative performance?, „Technovation” 2018, vol. 69(C), pp. 2-14.

Sánchez Graells A. Public Procurement and the EU Competition Rules, Hart 2015.

Talebi A., Rezania D., Governance of projects in public procurement of innovation a multi-level perspective, "Journal of Public Procurement” 2020, vol. 20, iss. 2.

Trybus M., The division of public contracts into lots under directive 2014/24, „European Law Review” 2018, vol 43, nº 3, pp. 313-342.

Uyarra E. et al., Barriers to innovation through public procurement: a supplier perspective, „Technovation” 2014, vol. 34, iss. 10, pp. 631-645.

Uyarra E., Edler J., Gee S., Georghiou L., Yeow J., Public procurement for innovation: the UK case, en L. Lember, T. Kalvet, R. Kattel (Eds.), Public procurement policy for innovation: International perspectives, New York 2013, pp. 233-257.

Valcárcel Fernández P., La innovación como objeto prestacional en los contratos del sector público. La Compra Pública de Innovación, „Contratación administrativa práctica: revista de la contratación administrativa y de los contratistas" 2018, n 153, pp. 56-68.

Zabala-Iturriagagoitia J.M., La Política de Compra Pública como Estímulo a la Innovación y el Emprendimiento. „Journal of Technology Management \& Innovation” 2017, vol. 12, nº 1, pp. 100-108. 
